\title{
Effects of Emotional Needs on Participation of Children Aged 4-6 with Learning Disabilities In Early Childhood Centers in Starehe Division, Nairobi County, Kenya
}

\author{
Ganira Khavugwi Lilian ${ }^{1}$, Paul Amolo Odundo ${ }^{1, *} \&$ Boniface Ngaruiya ${ }^{1}$ \\ ${ }^{1}$ Department of Educational Communication and Technology, School of Education, University of Nairobi, Nairobi, \\ Kenya \\ *Corresponding author: Department of Educational Communication and Technology, School of Education, University \\ of Nairobi, Nairobi, Kenya. E-mail: odundopaul@yahoo.com
}

Received: April 8, $2015 \quad$ Accepted: May 18, $2015 \quad$ Online Published: June 8, 2015

doi:10.5430/wje.v5n3p79 URL: http://dx.doi.org/10.5430/wje.v5n3p79

\begin{abstract}
During early childhood, the foundations for emotional, social and spiritual well being of children with learning disabilities (CWLD) are laid. The CWLD emotional well being is influenced by all the experiences they go through. It is essential to provide warm, trusting relationships, predictable and safe environment, affirmation and respect for all aspects of children's emotional, physical, social, cognitive and linguistic well being of CWLD. There is need to actively seek to remove the barriers to learning and participation, meet emotional needs in a positive and pro-active way and engender a sense of community in an inclusive Early Childhood Education (ECE) environment. The study assesses the effects of emotional needs on participation of (CWLD) in (ECE) centers in Starehe division in Nairobi County. In its methodology the study uses structured interview and observation as the principle data collection instruments. Likewise, it employed a descriptive research design to gather data. The target population was 5 head teachers, 35 teachers, 20 children aged 4-6 with learning disabilities and 20 parents of children with learning disabilities. Purposive sampling and simple random sampling were used for this study. Analysis was obtained through editing, coding, classifying and tabulation processes. It was established that emotional needs of (self concept, social competence and respect) which teachers effectively engaged yielded encouraging results in an inclusive ECE learning environment. However, the findings draw attention to inadequacies in the current ECE system of identifying emotional needs for CWLD.
\end{abstract}

Keywords: early childhood education; emotional needs; inclusive learning environment; learning disability; participation

\section{Introduction}

Meeting emotional needs of children living with learning disabilities lays a foundation for their future Francis et al., (2005). A dependable source of self-concept, respect and social-competence develops a healthy capacity to trust and accurate self image which in turn provides CWLD with tools they need for sustained participation and effectively overcome life's adversities Marinak \& Gambrell (2008). With full emotional needs met, the CWLD will be ready to actively participate in an inclusive ECE environment. However ECE curriculum emphasizes on cognitive and academic preparedness which shadows the importance of emotional needs.

Despite various studies on CWLD, many issues remain underexplored when it comes to emotional needs Schulte (2002). After realizing the desperate need for quality ECE for CWLD, UNESCO (2006) declared every child's entitlement to a basic education and participation in school and in community. Furthermore, in the year 2000, member states committed to serve vulnerable and disadvantaged children by signing the Darker Framework for Action UNESCO (2001). Currently however, these goals are not met. Stigma, ignorance and neglect are still barriers for participation for CWLD.

According to Smith (2007) when CWLD grow up to their best to satisfy their childhood emotional needs and if the needs are not met, CWLD experience emotional pain. To mitigate such emotional pain there is need for ECE curriculum to focus on skills that will foster high participation for CWLD. These skills include (responsibility, 
self-worth, decision-making, independence, self- regulating citizenship, confidence, competent, and self regulating). Effective support for CWLD's mental health and well being involves efforts to meet their emotional needs Waraich et al., (2004). If CWLD feel safe secure and included they can be themselves and be honest about what their needs are.

Learning disabilities result from impairments in one or more processes related to perceiving, thinking, remembering or learning Brown et al., (2008). These include but are not limited to language processing, phonological processing, visual spatial functions, processing speed, memory and attention. Studies by Cook et al., (2008) indicate that CWLD have the potential to lead happy and productive lives and to make significant contributions to society. However, when their difficulties are not recognized and appropriate interventions and supports not provided, there are negative consequences of significantly under achieving, high levels of stress, school drop outs and poor mental, emotional and physical health which inhibit participation of CWLD.

In order to create a positive inclusive ECE learning environment for CWLD, it is important to assess and enhance their self concept. Studies by Comer (2001) shows that CWLD feel emotionally safe when adults in their life's care about them and support them. Theories of self-concept argue that an ECE programme can foster children's self-concept and build the foundation for future relationships with others Cowie \& Carr (2004). To this end, ECE teachers need to structure the classroom and respond in ways that contribute to general participation for CWLD at the same time concrete representations and pictorial understanding of new concepts to more abstract forms. If this is done CWLD will feel emotionally connected and connections build positive relationships which are foundations for confidence and improved learner participation.

Studies by Schimmack (2005) found that learners achieve lower in terms of their potential if they have low selfconcept. This position is further supported by Berger (2000) who argued that learners who willingly accept their limitations perform better academically. For sustained learner participation to be realized CWLD require a safe and supportive environment that promotes their well being and development. This can be achieved if teachers set clear guidelines for behavior, set high but achievable expectations tailored to a CWLD's participation at the same time lead to improved social engagement and self-respect.

Further studies by Gilmore et al., (2003) revealed that one's self-concept influences behavior, cognitive and emotional outcomes including academic levels of happiness, anxiety, social integration, self worth and life satisfaction. The CWLD whose self-concept is positive will effectively participate in school and in the community. In order to realize optimal participation for CWLD there is need to set practical tasks and activities that promote decision making skills. In addition, teachers should take time with CWLD and talk about their frustrations and anxiety and empower CWLD to achieve their full potential Williams (2003). This is likely to energize CWLD to participate in learning, gain capacity in decision making, responsibility and respect.

According to Kelly \& Norwich (2004) the evaluations that individuals have about themselves and their competencies are vital aspects of self that may influence all other aspects of conduct and psychological well-being. Similarly CWLD whose self-concept is low are likely to experience less learner participation. Furthermore, studies by Judge et al., (2005) revealed that core self-evaluations measured in childhood are linked to later job satisfaction in later years. In the same vein it is important for CWLD to develop positive self-concept in order to effectively participate in school and in society. In order to boost participation for CWLD there is need for parents to encourage the belief that positive self-concept can be achieved by providing a range of learning and development opportunities as well as positive conversations. When this is done there are high chances of learner participation.

Analysis by Manning et al., (2006) indicates that self-concept develops as a result of experiences with the environment and one's evaluation of these experiences. Additionally, opinions of significant others, casual attributions, and concrete feedback play a crucial role in the process of self-concept development Pomeroy (2006). This can be attained through positive family communications, warm trusting relationships, predictable and safe environment and affirmation and respect for all aspects of well being. When this is achieved, there is likelihood of high learner participation.

Studies by Baker \& Scher (2002) revealed that, when parents were positively involved in the lives of their children, the self-concept of their children was affected in a positive way. Similarly having positive parental involvement in the life of CWLD helped in facilitating their self-concept Fan \& Chen (2001) Thus to foster high participation for CWLD, it is essential for parents to give positive feedback; words of encouragement and genuine belief in CWLD's abilities produce positive feelings which in turn transcends to high participation.

Further studies by Stoner et al., (2005) showed that when parents interacted with CWLD frequently positive 
outcomes occurred. Conversely, when the interaction was minimal, negative self-concept resulted Murray \& Curran (2008). In order to encourage CWLD to participate, there is need for parents to explore various options for the betterment of communication with CWLD. When a sense of positive self-concept is realized, CWLD are likely to develop a strong sense of responsibility, self-worth and decision making which are key ingredients for high participation.

Respect is a crucial component of successful participation for CWLD. According to UNICEF (2003) CWLD have the right to receive educational services in a manner that respects their dignity. As CWLD experience what it is to feel respected and these needs become a home and school value, they are likely to become competent, confident and develop a sense of social integration. Thus for high participation to be realized there is need for teachers and learners to foster mutual respect for CWLD in and out of classroom. Analysis by Lieberman et el., (2008) revealed that positive contact with CWLD is the only effective way to help them gain understanding and knowledge. In this regard teachers need to develop cooperative relationships and interact positively with CWLD in order to facilitate effective participation. Teachers should also engage in one-on one interaction with CWLD in a calm pleasant manner, foster secure attachment and help CWLD develop skills leading to high participation.

In addition to being able to interact cooperatively CWLD benefit from gaining an appreciation for diversity. Dunbar \& Villarruel (2004) suggested that schools can help to develop tolerance and respect for differences in CWLD by teaching empathy and anger management skills and also promoting respect for CWLD. This can be achieved through treating CWLD with fairness, respect and understanding and speaking to them in a calm respectful tone and assisting CWLD in identifying and expressing feelings in a culturally and socially acceptable way. If this is achieved, CWLD are likely to be motivated to actively participate in learning.

Further still to be ready to participate constructively in classroom and in society, CWLD need to be respected. Self-respect influences confidence in one's merit as a person. Studies by Kawamura et al., (2002) provided recommendations for promoting respect between learners with and without disabilities. Included in their list were cooperative learning groups which they indicated could provide both social and academic benefits for CWLD. Additionally Biswas at el., (2010) opined that teachers should engage learners in collaborative problem solving e.g. (through regular classroom meetings) in order to provide learners a voice for concerns related to CWLD and to help them develop understanding. When this is realized, CWLD are likely to develop the spirit of social integration which will in turn motivate CWLD to effectively participate in school activities.

Studies by Buyse et al., (2009) pointed out that respectful learner-teacher relationships contribute to academic success and an optimistic outlook on self and schooling. Similarly when ECE centers encourage positive social interaction and provide opportunities for CWLD to learn from each other, high participation can be achieved. Teachers therefore need to encourage CWLD to accept their own identity and intrinsically value who they are. This sense of self-respect is likely to motivate CWLD to actively participate. Further studies by Wu et al., (2010) showed that for learners to develop knowledge and self-efficacy to realize their full potential they require respect. Learners who are active co-creators of their own learning, develop the ability, confidence and motivation to succeed academically Clark (2010). Likewise for successful participation to be achieved, teachers need to model respect as a powerful curative to the intolerance, inequality, discrimination and power differences in schools. When this is done, the participation for CWLD likely to be realized.

Feeling respected is an important part of being human. People require standing respect, a feeling of worthiness, and collective identity Jordan et al., (2003). The CWLD need to be respected for their sustained participation to be realized. Teachers need to focus on the learners' capabilities and not disabilities, be patient with CWLD, be respectful and offer assistance and be considerate of feelings of CWLD. Studies by Cohen et el., (2006) revealed that lack of respect by peers was associated with poor relations. For high learner participation to be achieved, CWLD require a social environment where mutual respect can be fostered. Hence the role of the teacher as a facilitator of mutual respect and social integration in the classroom plays an integral part in learner participation. This can be achieved through respecting one another's right to a different opinion, helping the CWLD to prepare for an upcoming transition or change by talking to CWLD and re-assuring them that you will be there to help, and giving adequate time for CWLD to complete tasks. These types of activities are prone to enable CWLD to feel respected and accommodated hence high participation.

For CWLD the ability to use social competence in every aspect of life facilitates high participation yet this skill is rarely addressed on the individual's education and transitions plans. According to Gresham et al., (2001) without adequate social competent skills, a person may experience trouble in areas of daily living skills, independent living and participation in the community. Additionally, analysis by Degnan et al., (2008) indicates that poor peer 
relationships and low social competent skills have been linked to drop-outs and juvenile delinquency. The CWLD must display appropriate competent skills within their culture to maintain relationships that will help them be successful, independent, self-regulated, and concerned citizens. Providing opportunities within the ECE curriculum for the development of these skills can assist CWLD in sustained participation. Analysis by Pavri \& Luftig, (2000) indicates that CWLD frequently have trouble making themselves understood for instance, being unable to ask questions or express their needs creates barriers which may lead to inter-personal problems such as making friends, working in groups, and self-control. Based on this realization, providing a culture of acceptance for CWLD in the classroom environment is of utter most importance for high participation. With this in mind, teachers need to provide as many opportunities as possible for CWLD to interact and work in teams.

Further analysis by Hwang \& Hughes (2000) indicates that CWLD lack social competent skills. Consequently, children who are labeled as learning disabled are more likely to have emotional problems, low self-esteem and conduct deficiencies Pavri (2001). Based on these findings teachers should focus on the development of social competency if sustained learner participation has to be realized for CWLD. In achieving social competence, there is need to practice positive eye-contact, listening and responding to the needs of CWLD and giving and receiving compliment. These positive attributes are likely to enable CWLD to gain independence that will facilitate active participation. Analysis by Blair \& Diamond (2008) has it that self-regulation of behavior is promoted when CWLD are encouraged and accepted, while maintaining clear structures and expectations. Thus a positive learning environment and high levels of learner engagements are essential for high learner participation. For self-regulation to be achieved, teachers need to provide information visually, orally and graphically where possible. Teachers also need to validate learner's feelings, abandon the task and focus on the person and incorporate the CWLD's interests into the lesson plan Desimone et al., (2002). This is likely to reinforce the importance of sustained high learner participation.

In successful programming for CWLD the environment must be structured to allow individual strength and development of social competence for every learner. Studies by Avramidis et al., (2000) revealed that the classroom is where CWLD have the most trouble. Although the classroom has rules which may vary from the rules of society, CWLD are expected to be multi-faceted and socially competent Pavri \& Luftig, (2000). In order to encourage CWLD to actively participate it is important for teachers to build up CWLD's personal profile through highlighting the strength, abilities, celebrating their success, spending personal discussion times with CWLD and providing consistent routines, clear rules and logical sequences. When this is realized there is likelihood of sustained learner participation.

\section{Statement of the Problem}

When CWLD emotional needs are met, healthy behavior naturally follows. With unmet emotional needs, frustrations and higher chances to have serious health problems including depression, distress, anxiety and anger, which impairs sustained learner participation. By clearly providing emotional needs of self-concept, respect and self-competent there is higher probability of high participation in an inclusive ECE learning environment. Additionally, CWLD are likely to acquire skills of (responsibility, self- worth, decision making, confidence, competence, social-integration, independence, citizenship and self-regulating respectively).

The CWLD have the right to be educated in the least restrictive but most appropriate environment, not only school phenomenon, but in the larger society. The CWLD can successfully participate if their emotional needs are met and if they are accorded the same treatment as those without learning disabilities. Providing emotional needs is likely to facilitate ultimate success and sustained participation. Hence the need to conduct this study.

\section{Purpose and Objectives.}

The broad objective of this study was to identify emotional needs of CWLD in pre-schools in Starehe Division in Nairobi County. The exercise was intended to provide useful information to the Ministry of Education (MOE), Policy makers and National Center for Early Childhood Education (NACECE) in understanding emotional needs of CWLD. Specifically the study set out to encourage MOE to invest in assisting CWLD.

\section{Theoretical Framework}

The study was founded on the theoretical framework of Abraham Maslow (1998). The theory states that individuals aim to meet their needs in the form of a hierarchy. Occasionally, some needs are met at the same level. By implication if CWLD emotional needs are not met effective participation will be impaired but once the needs are met, 
CWLD may then move to the next level in the hierarchy.

Self-concept: For the CWLD to participate, they need skills that will foster responsibility, self-worth and decision making. Teachers need to develop class guidelines by involving CWLD and at the same time create special and celebratory days e.g. Birthdays. They also need to design classroom decorations, make small groups of decision makers, and identify classroom theme, flags and songs. This is the level of self-evaluation where CWLD begin to explore and model, designing, evaluating and analyzing information.

Respect: creating a positive environment in which CWLD are respected and celebrated enhances high participation. For the CWLD to feel capable and successful in participation the ECE environment must be conducive for CWLD to demonstrate their expertise. Teachers should create and design quizzes, assignments and instructions that cater for the needs of CWLD. This can be achieved through dialogue, showing respect and compassion to CWLD and use of positive language in describing a need or desire.

Social-competence: In order to interact socially CWLD need to be competent in communication skills. This is the most fundamental skill for high participation, therefore CWLD need constant feedback on what they do correctly or incorrectly in order to improve their participation. Modeling and role playing from teachers and peers can assist in providing positive feedback for CWLD.

\section{Conceptual Framework}

The conceptual framework used in this study helps to explain the influence of emotional needs (self-concept, respect and social competent) on the participation of CWLD. Unmet emotional needs can inhibit a CWLD future and participation. However with full provision of emotional needs, CWLD are ready to actively participate in school and in the community. The development of the skills attitudes and knowledge that fosters (responsibility, self-worth, decision making, confidence, competent, social-integration, independence, citizenship and self-regulating) promotes sustained participation for CWLD.



Figure 1. Conceptual Framework

\section{Data and Methodology}

Research methodology is an approach and a set of supporting methods and guidelines to be used as a framework for doing research design Blessing \& Chakrabarti (2009). This study employed a descriptive research design to gather data. Descriptive studies portray an accurate profile of persons, events or situations Chandran (2003) and describe existing conditions and attitudes through observation and interpretation techniques. The design was appropriate for this study to 
accurately capture data from the various intervention measures adopted by the preschools and impact of those interventions on the participation of CWLD. The use of qualitative research methods in this study provided opportunity to examine and interpret patterns of instruction used by teachers.

Population is the aggregate of all that conforms to a given specification. Mugenda \& Mugenda (2003). Simple random sampling technique was used to identify five pre-schools. This method reduces bias in sample selection and provides the basis of making statistical inferences to the population from which the representative sample is drawn Chandran (2003). Purposive sampling and simple random sampling were then used for this study to obtain a target population of 5 head teachers, 35 teachers, 20 parents and 20 CWLD aged 4-6. According to Kerlinger (2003), purposive sampling is characterized by the use of judgment and deliberate effort to obtain a representative sample while reducing error and increasing possibilities in analysis. Purposive sampling is useful in qualitative research design and especially in cases where data illustrates characteristics of particular subgroups of interest and also facilitates comparison, and investigator relies on expert judgment to select units that are representative or typical of the population Patton, (2002).

The sampling frame displayed shows how respondents were distributed in the sample of this study as shown in table 1 .

Table 1. Sampling Frame of the Study

\begin{tabular}{lc}
\hline Sample & No. \\
\hline Head teachers & 5 \\
Teachers & 35 \\
Parents & 20 \\
Children with learning disabilities & 20 \\
\hline
\end{tabular}

According to Mugenda \& Mugenda (2003), the most commonly used instruments of data collection are questionnaires, interview schedules, observations forms, standardized tests and content analysis. Instruments of data collection for this study were questionnaires, interview schedules and observation guide. The questionnaire was administered to teachers and it dealt with teachers' views on participation of CWLD. An interview schedule was used to obtain information from head teachers and parents on their views concerning emotional needs of CWLD. The interview schedule was used on CWLD to obtain their views on their emotional needs.

Data analysis is the process of bringing order, structure and meaning to the mass of information collected. According to Jackson (2009), descriptive research design is commonly represented by use of frequency charts, bar graphs and pie charts to tabulate the information gathered appropriately. Data collection for this study was obtained through editing, coding and tabulation procedures.

Table 2. Years of Service and Academic Qualifications of the Respondents

\begin{tabular}{lllllllll}
\hline $\begin{array}{l}\text { No. of Years of } \\
\text { Service }\end{array}$ & Frequency & $\%$ & $\begin{array}{l}\text { No. of Years of } \\
\text { Service in } \\
\text { Current Station }\end{array}$ & Frequency & $\begin{array}{l}\text { \% } \\
\text { Academic } \\
\text { qualification } \\
\text { of teachers }\end{array}$ & Frequency & \% \\
\hline$<1$ year & 0 & 0 & $<1$ year & 0 & 0 & P1 teachers & 8 & 22.8 \\
1-2 years & 5 & 14.3 & 1-2 years & 3 & 8.6 & Diploma & 12 & 34.3 \\
2-5 years & 6 & 17.1 & $2-5$ years & 10 & 28.6 & Bachelors & 13 & 37.1 \\
$5-9$ years & 10 & 28.6 & $5-9$ years & 18 & 51.4 & Masters & 2 & 5.7 \\
$>$ 10 years & 14 & 40.0 & $>10$ years & 4 & 11.4 & & & $\mathbf{1 0 0}$ \\
Total & $\mathbf{3 5}$ & $\mathbf{1 0 0}$ & Total & $\mathbf{3 5}$ & $\mathbf{1 0 0}$ & Total & $\mathbf{3 5}$ & $\mathbf{1 0 0}$ \\
\hline
\end{tabular}

\section{Study Findings}

From table 2, cumulatively 5(14.3\%) out of 35 teachers had between $1-2$ years of experience, $6(17.1 \%)$ had between 2-5 years of experience, $10(28.6 \%)$ had between 5-9 years of experience while $14(40 \%)$ had over ten years of experience. This depicts that apart from 5(14.3\%) who had only 1-2 years of experience, the majority of the teachers had more than ten years of experience indicating that they were well trained and equipped with prerequisite knowledge that enabled them to handle CWLD. Out of 35 teachers $3(8.6 \%)$ had taught in the station from between 1-2 years, 10(28.6\%) had taught in the same station for between 2-5 years, 18(51.4\%) had taught for 5-9 years in the same station while $4(11.4 \%)$ had taught for over ten years in the same station. This indicates that the majority 
$18(51.4 \%)$ of those who had taught in the same station had experience in handling CWLD. Consequently, $8(28.8 \%)$ out of the 35 teachers had P1 certificates, 12(34.3\%) had diploma, 13(37.1\%) had Bachelors degree while 2(5.7\%) had Masters in Early childhood education. This indicates that the majority of teachers need to be well trained to handle CWLD.

The study sought to investigate the prevalence of learning disabilities in Starehe division.

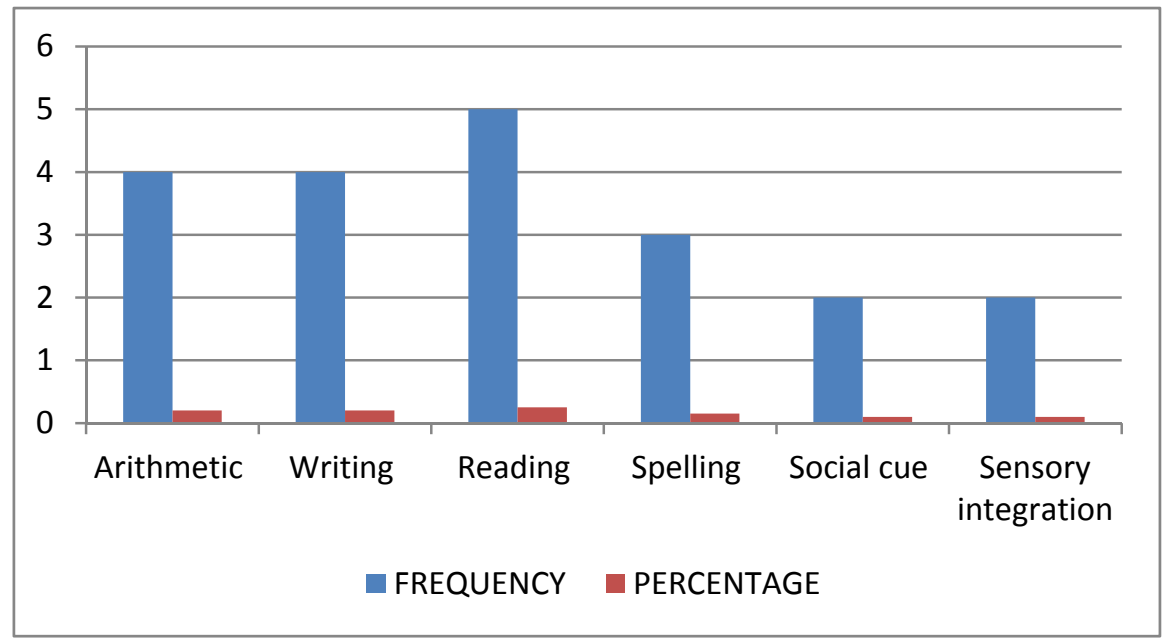

Figure 2. Prevalence of Learning Disabilities in Starehe Division

From figure 2 the study found that 4(20\%) out of 20 CWLD had arithmetic disability, 4(20\%) had writing disability, $5(25 \%)$ had reading disability, 3(15\%) had spelling disability, while 2(10\%) had social cue disability and sensory integration disability respectively. These findings imply that the most common form of learning disability is reading, writing, and arithmetic disabilities.

The study sought to examine teachers' understanding of emotional needs and participation of CWLD.

Table 3. Teachers' Understanding of Emotional Needs of CWLD

\begin{tabular}{|c|c|c|c|c|}
\hline \multirow[t]{3}{*}{ Item } & \multicolumn{4}{|c|}{ Views } \\
\hline & \multicolumn{2}{|c|}{ Yes } & \multicolumn{2}{|l|}{ No } \\
\hline & No. & $\%$ & No. & $\%$ \\
\hline \multicolumn{5}{|l|}{ Self-concept } \\
\hline Do you involve CWLD in responsibility activities? & 20 & 57.14 & 15 & 42.86 \\
\hline Do CWLD appreciate who they are? & 25 & 71.43 & 10 & 28.57 \\
\hline Do CWLD participate in decision making activities? & 19 & 54.19 & 16 & 46.71 \\
\hline \multicolumn{5}{|l|}{ Social competence } \\
\hline Are CWLD independent? & 10 & 28.57 & 25 & 71.43 \\
\hline Do CWLD take turns and listens to responses? & 13 & 57.14 & 22 & 62.86 \\
\hline Do CWLD understand what to do when they have problems? & 24 & 68.57 & 12 & 31.43 \\
\hline \multicolumn{5}{|l|}{ Respect } \\
\hline Can CWLD present work in a way that can be understood by others? & 22 & 62.86 & 13 & 37.14 \\
\hline Can CWLD follow more than one instruction effectively? & 19 & 54.28 & 16 & 45.71 \\
\hline Do CWLD appear to learn better in groups or alone? & 18 & 51.43 & 17 & 48.57 \\
\hline
\end{tabular}

From table 3, the study found that 20(57.14\%) out of the 35 teachers reported having involved CWLD in responsibility activities while $15(42.86 \%)$ did not. Similarly $25(71.43 \%)$ reported that CWLD appreciated who they while $10(28.57 \%$ ) did not. Furthermore $19(54.19 \%)$ allowed CWLD to participate in decision making while 16(46.71) did not. From the findings, one would argue that most teachers involved CWLD in self-concept activities. 
These findings corroborate with findings of Cowie \& Carr (2004) that self-concept influences behavior, cognitive and emotional outcomes.

Out of 35 teachers 10(28.57\%) reported that CWLD were independent while 25(71.43\%) reported that CWLD were not independent. This depicts lack of commitment by teachers to develop independence in CWLD. Concerning citizenship 13(57.14\%) reported that CWLD take turns and listens to responses while 22(62.86\%) did not, $24(68.57 \%)$ reported that CWLD understood what to do when they had problems while $12(31.43 \%)$ did not. These findings indicate that there was inadequacy in provision of social competence skills. These findings confirm studies by Schimmack (2005) that the classroom is where CWLD have most trouble, although CWLD are expected to be multi-faceted and socially competent Pavri \& Luftig, (2000)

Cumulatively 22(62.86\%) out 35 teachers reported that CWLD presented their work in a way that can be understood by others while $13(37.14 \%)$ did not. Additionally 19(54.28\%) reported that CWLD followed more than one instruction effectively while $16(45.71 \%)$ did not, $18(51.43 \%)$ appeared to learn better in groups than alone while $17(48.57 \%)$ did not. This indicates that most of the teachers understood the importance of respecting CWLD. These findings agree with the argument of Jordan et al., (2003) that CWLD develop knowledge and self-efficacy to realize their full potential when they are respected. In one incident a teacher commented ................ am tired of repeating the same sounds everyday. This boy is very slow. He cannot master sums however much I repeat them. I will not spend all my energies on one boy when the rest of my class needs my attention.

The study sought to find out parents' understanding of emotional needs of CWLD and also the CWLD understanding their emotional needs.

Table 4. Parents and CWLD Understanding of Emotional Needs and Participation

\begin{tabular}{|c|c|c|c|c|c|}
\hline \multirow[b]{2}{*}{ ITEM } & & \multirow{2}{*}{$\begin{array}{l}\text { YES } \\
\text { NO. }\end{array}$} & \multicolumn{3}{|c|}{ NO } \\
\hline & & & $\%$ & NO. & $\%$ \\
\hline i. & Do you give your responsibilities to your disabled child? & 16 & 80 & 4 & 20 \\
\hline ii. & Do your disabled willingly accept his limitations? & 12 & 60 & 8 & 40 \\
\hline iii. & Do you involve your child in decision making? & 6 & 30 & 14 & 70 \\
\hline iv. & Do you built independence to your disabled child? & 14 & 70 & 6 & 30 \\
\hline v. & Do you develop citizenship skills to your disabled child? & 11 & 55 & 9 & 45 \\
\hline vi. & Is your disabled child self-regulating? & 8 & 40 & 12 & 40 \\
\hline vii. & Do you develop confidence skills in your disabled child & 10 & 50 & 10 & 50 \\
\hline viii. & Do you develop competence skills to your disabled child? & 8 & 40 & 12 & 60 \\
\hline ix. & Do you encourage positive, social integration to your disabled child? & 10 & 50 & 10 & 50 \\
\hline \multirow{2}{*}{\multicolumn{2}{|c|}{ The CWLD's view }} & Yes & & No & \\
\hline & & No & $\%$ & No. & $\%$ \\
\hline i. & Do you accept responsibility? & 16 & 80 & 4 & 20 \\
\hline ii. & Are you able to make your own decisions? & 15 & 75 & 5 & 25 \\
\hline iii. & Do you have problems completing a task? & 10 & 50 & 10 & 50 \\
\hline iv. & Do you like sharing ideas with your peers? & 14 & 70 & 6 & 30 \\
\hline v. & Do you speak to your peers in a calm and respectful tone? & 13 & 65 & 7 & 35 \\
\hline
\end{tabular}

From table 4 the study found that $16(80 \%)$ out of the 20 parents gave responsibilities while $4(20 \%)$ did not. The findings also indicate that $12(60 \%)$ had disabled children who willingly accepted their limitations while $8(40 \%)$ did not. This indicates that unless parents take initiative in developing skills that foster self-concept then the participation for CWLD will be inadequate. These findings agree with studies by Gilmore et al., (2003) that when the interaction between parents and CWLD is minimal negative self-concept results.

Further findings indicated that 14(70\%) built independence while 6(30\%) did not, consequently 11(55\%) developed citizenship skills in CWLD while 9(45\%) did not. Additionally, 8(40\%) had self-regulated CWLD while 12(40\%) were not. These findings imply that there was laxity on the part of parents' roles in providing social competence skills efficiently. These findings agree with the findings of Cowie \& Carr (2004) that when parents are positively involved in the lives of CWLD then their self-concept is affected in a positive way.

Cumulatively, $10(50 \%)$ of the parents developed confidence skills in CWLD, 10(50\%) did not, $8(40 \%)$ developed competence skills in CWLD while $12(60 \%)$ did not. Additionally $10(50 \%)$ encouraged positive social integration 
while 10(50\%) did not. These findings imply that unless parents take initiative in respecting the CWLD needs then sustained participation will be impaired. These findings corresponds with the findings of Lieberman et al., (2008) that positive contact with CWLD is the only effective way of helping them gain knowledge and understanding. In one incident a parent commented that

............my daughter feels good when she is valued, respected and praised. When she is with people, friends and peers she feels included and has a lot of confidence but she feels sad when excluded

Further findings showed that $16(80 \%)$ out of 20 CWLD accepted responsibility while $4(20 \%)$ did not. Additionally, $15(75 \%)$ made their own decisions while $5(25 \%)$ did not. Consequently, 10(50\%) CWLD had problems in completing tasks while $10(50 \%)$ did not, $14(70 \%)$ CWLD indicated that they liked sharing ideas with peers while, 6(30\%) did not. Additionally 13(65\%) CWLD spoke in calm and respectful tones, 7(35\%) did not. These findings indicate that most of the CWLD had developed the skills of responsibility, decision-making and respect. These findings coincide with the findings of Lieberman et el., (2008) that promoting social interactions between learners with and without disabilities improved confidence in CWLD. In one incident a child lamented that ..........my teachers calls me "lazy" and my classmates ridicule me because of my poor handwriting, however much I try it doesn't come out clearly. No one is patient with me nor values what I do. I do not know what I can do to improve on my writing skills, I need help. The study sought to investigate the views of head teachers on participation of CWLD.

Table 5. Views of Head Teachers on Participation by CWLD

\begin{tabular}{lllll}
\hline \multirow{2}{*}{ Item } & \multicolumn{2}{l}{ Strongly agree } & Agree & NO. \\
\cline { 2 - 5 } & NO. & $\mathbf{\%}$ & NO. & 20 \\
\hline CWLD needs responsibility skills & 4 & 80 & 1 & 20 \\
CWLD needs to acquire their self-worth & 4 & 80 & 1 & 40 \\
CWLD need to be involved in decision-making & 3 & 60 & 2 & 0 \\
CWLD needs to be independent & 5 & 100 & 0 & 40 \\
CWLD need to be taught citizenship skills & 3 & 60 & 2 & 0 \\
CWLD need to be taught self-regulation skills & 5 & 100 & 0 & 0 \\
CWLD need to build confidence & 5 & 100 & 0 & 40 \\
CWLD need to taught competent skills & 3 & 60 & 2 & 20 \\
CWLD need social integration skills & 4 & 80 & 1 & \\
\hline
\end{tabular}

The findings from table 5 depicts that $4(80 \%)$ out of 5 head teachers strongly agree that CWLD need responsibility skills while $1(20 \%)$ agree. Additionally $4(80 \%)$ strongly agree that CWLD require their self-worth while $1(20 \%)$ agree. Furthermore 3(60\%) strongly agree that CWLD need to be involved in decision-making while 2(40\%) agree. These findings indicate that majority of head teachers understands the importance of self-concept for CWLD. These findings agree with the findings of Pomeroy (2006) that ECE programmes can foster CWLD self-concept and built the foundations for future relationships with others.

Cumulatively, 5(100\%) strongly agree that CWLD need to be independent while 3(60\%) strongly agree that CWLD need to be taught citizenship skills. Additionally 5(100\%) strongly agree that CWLD required self-regulating skills. This indicates that majority of head teachers understand the importance of social competence skills in participation for CWLD. These findings agree with the findings of Gresham et al., (2001) that social competence plays and integral part in how well a young person transits into adulthood.

Further findings showed that $5(100 \%)$ head teachers strongly agree that CWLD need confident skills, 3(60\%) strongly agree that CWLD need competent skills while $2(40 \%)$ agree. Additionally $4(80 \%)$ strongly agree that CWLD need social integration skills while $1(20 \%)$ agree. These findings indicate that majority of head teachers understand the importance of respecting CWLD. These findings corroborate Blair \& Diamond (2008) who argue that CWLD benefit from gaining an appreciation for diversity. In one instance a head teacher said:..........these children need a lot of support from parents, teachers and their peers. The learning disabilities should not deter them from realizing their full potential, though one needs to be very patient when handling them.

\section{Conclusions}

The study investigated the effects of emotional needs on the participation of CWLD. Results suggests that majority of teachers handling CWLD understood their emotional needs although there were inadequacy in providing 
emotional needs in totality. The literature review identified trends concerning emotional needs of CWLD as self-concept, respect and self-competence. It also identified models of effective practice currently being implemented in the schools' settings to meet emotional needs of CWLD. It was evident that head teachers understood the importance of providing emotional needs and their positive attributes contributed to learner participation. However, the various types of learning disabilities post a challenge to teachers owing to lack of proper training in Handling CWLD. Consequently parents' laxity in providing adequate emotional needs was noted.

\section{Recommendations}

Based on the conclusions, the researcher made the following recommendations:

1. The Government and the Ministry of Education should promote awareness and the importance of emotional needs to CWLD.

2. Provision of emotional needs of self concept, social competence and respect should be strengthened in ECE learning environment.

3. The Ministry of Education should ensure that ECE learning environment tailor their facilities to suit emotional needs of CWLD.

4. Mechanisms should be put in place to mitigate barriers to participation of CWLD.

5. There is need for strong legislation, policy and practice across ECE school system.

\section{References}

Ary D., Jacobs LC., Razavieh A., \& Sorensen C. (2006). Introduction to Research in Education (7th ed.). Belmont, CA: Thomson.

Avramidis, E., Bayliss, P., \& Burden, R. (2000). A Survey into Mainstream Teachers' Attitudes Towards the Inclusion of Children with Special Educational Needs in the Ordinary School in one Local Education Authority. Educational Psychology, 20(2), 193-213. http://dx.doi.org/10.1080/713663717

Baker, L., \& Scher, D. (2002). Beginning readers' motivation for reading in relation to parental beliefs and home reading experiences. Reading Psychology, 23, 239-269. http://dx.doi.org/10.1080/713775283

Berger, J.B. (2000). Optimizing capital, social reproduction and understanding persistence In Reworking the student Departure puzzle, edited by J. Braxton. Nashville, TN: Vanderbilt university press.

Biswas, G., Jeong, H., Kinnebrew, J. S., Sulcer, B., \& Roscoe, A. R. (2010). Measuring self regulated learning skills through social interactions in a teachable agent environment. Research and Practice in Technology-Enhanced Learning, 5(2), 123-152. http://dx.doi.org/10.1142/S1793206810000839

Blair, C., \& Diamond A. (2008). Biological Processes in Prevention and Intervention: The Promotion of Self-Regulation as a Means of Preventing School Failure. Development and Psychopathology, 20, 899-911. http://dx.doi.org/10.1017/S0954579408000436

Blessing, TM. Lucienne \& Ameresh Chakrabart, DRM. (2009). A Design Research Methodology. Springer Verlay, London, U.K.

Brown, K.S., Welsh, L.A., Haegele Hills, K., \& Cipko, J.P. (2008). The efficacy of embedding special education instruction in teacher preparation programs in the United States [Electronic version]. Teaching and Teacher Education, 8(24), 2087-2094. http://dx.doi.org/10.1016/j.tate.2008.02.013

Buyse, E., Verschueren, K., Verachtert, P., \& Van Damme, J. (2009). Predicting school adjustment in early elementary school: Impact of teacher-child relationship quality and relational classroom climate. Elementary School Journal, 110(2), 119-141. http://dx.doi.org/10.1086/605768

Chandran VGR \& Veera P. (2003). Research Methodology. A simple Guide for Business Undergraduates. University Publication Centre, UITM press.

Clark, R. E. (2010). Disagreement about the benefits of different levels of instructional guidance. In R. Reiser and J. Dempsey (Eds.), Trends and issues in instructional designand technology (3rd ed.). Upper Saddle River, NJ: Merrill/Prentice-Hall.

Cohen, R., Hsueh, Y., Hancock, M.H., Zhou, Z., \& Floyd, R. (2006). Respect, liking, and children's social 
competence in China and the United States. In D. W. Shwalb \& B. J. Shwalb (Issue Eds.), New directions for child and adolescent development Number 114: Respect and disrespect: Cultural and developmental origins (pp. 53-66). San Francisco:Jossey-Bass

Comer, J. (2001). Schools that develop children. The American Prospect, 12(7). Retrieved December 4, 2001, from http://www.prospect.org/print-friendly/print/V12/7/comer-j.html

Cook, B.G., Tankersley, M., \& Harjusola-Webb, S. (2008). Evidence-based special education and professional wisdom: Putting it all together. Intervention in School and Clinic, 44(2), 105-111. http://dx.doi.org/10.1177/1053451208321566

Cowie, B., \& Carr, M. (2004). The consequences of socio-cultural assessment. In Anning, C., Cullen, J. and Fleer, M. (eds.) (2004), Early childhood education: society and culture (pp.95-106). Delhi, New York and London: Sage Publications.

Degnan KA., Calkins SD., Keane SP., \& Hill-Soderlund AL. (2008). Profiles of disruptive behavior across early childhood: Contributions of frustration reactivity, physiological regulation, and maternal behavior. Child Development, 79, 1357-1376. http://dx.doi.org/10.1111/j.1467-8624.2008.01193.x

Desimone, L., Porter, A., Garet, M., Yoon, K., \& Birman, B. (2002). Effects of Professional development on teachers' instruction: Results from a three-year longitudinal study. Educational Evaluation and Policy Analysis, 24(2), 81-112. http://dx.doi.org/10.3102/01623737024002081

Dunbar, C., Jr., \& Villarruel, F. A. (2004). What a difference the community makes: Zero tolerance policy interpretation and implementation. Equity and Excellence in Education, 37, 351-359. http://dx.doi.org/10.1080/10665680490520215

Fan, X.T., \& Chen, M. (2001). Parental involvement and students' academic achievement: A meta-analysis. Educational Psychology Review, 13, 1-22. http://dx.doi.org/10.1023/A:1009048817385

Francis, D. J., Fletcher, J. M., \& Stuebing, K. K. (2005). Psychometric approaches to the identification of LD: IQ and achievement scores are not sufficient. Journal of Learning Disabilities, 38, 98-108. http://dx.doi.org/10.1177/00222194050380020101

Gilmore, L., Campbell, J., \& Cuskelly, M. (2003). Developmental expectations, personality stereotypes, and attitudes towards inclusive education: community and teacher views of Down syndrome. International Journal of Disability, Development and Education, 50(1), 67-78. http://dx.doi.org/10.1080/1034912032000053340

Gresham, F. M., Sugai, G., \& Horner, R. H. (2001). Interpreting outcomes of social skills training for students with high-incidence disabilities. Exceptional Children, 67(3), 331-344.

Hwang, B., \& Hughes, C (2000). The effects of social interactive training on early social communicative skills of children with autism. Journal of Autism and Developmental Disorders, 30, 331-343. http://dx.doi.org/10.1023/A:1005579317085

Jackson, SL. (2009). Research Methods And Statistics: A Critical Thinking Approach( $3^{\text {rd }}$ edition). Belmont, CA: Wadsworth.

Jordan, C. H., Spencer, S. J., \& Zanna, M. P. (2003). 'I love me...I love me not': Implicit self-esteem, explicit self-esteem and defensiveness. In Spencer, S. J., Fein, S., Zanna, M. P., \& Olsen, J. M., Motivated social perception: The Ontario symposium, 9. Mahwah, NJ: Erlbaum. pp. 117-145.

Judge, T. A., Bono, J. E., Erez, A., \& Locke, E. A. (2005). Core self-evaluations and job and life satisfaction: The role of self-concordance and goal attainment. Journal of Applied Psychology, 90, 257-268. http://dx.doi.org/10.1037/0021-9010.90.2.257

Kawamura, K. Y., Frost, R. O., \& Harmatz, M. G. (2002). The relationship of perceived parenting styles to $\begin{array}{lllll}\text { perfectionism. Personality and Individual } & \text { Differences, } & 32(2), & 317-327 .\end{array}$ http://dx.doi.org/10.1016/S0191-8869(01)00026-5

Kelly, N., \& Norwich, B. (2004). Pupils' perceptions of self and labels: Moderate learning difficulties in mainstream and special schools. British Journal of Educational Psychology, 74, 411-435. http://dx.doi.org/10.1348/0007099041552297

Kerlinger P. (2003). Addendum to the Phase I avian risk assessment for the Flat Rock Wind Power Project, Lewis County, New York: Phase One and Phase Two. March 31, 2003. Report to 111 Flat Rock Wind Power, L.L.C. 
Lieberman, L. J., Lytle, R. K., \& Clarcq, J. (2008). Getting it right from the start: Employing the universal design for learning. Journal of Physical Education, Recreation \& Dance, 79, 32. http://dx.doi.org/10.1080/07303084.2008.10598132

Manning, M. A., Bear, G. G., \& Minke, K. M. (2006). Self-concept and self- esteem. In G. G. Bear \& K. M. Minke (Eds.), Children's needs III: Development, prevention, \& intervention (pp.341-356). Washington, DC: National Association of School Psychologists.

Marinak, B., \& Gambrell, L. (2008). Intrinsic motivation and rewards: What sustains young children's engagement with text? Literacy Research and Instruction, 47(1), 9-26. http://dx.doi.org/10.1080/19388070701749546

Maslow A, (1998). Towards a psychology of being $\left(3^{\text {rd }}\right.$ ed.) New York: Wiley \& Sons.

Mugenda M.O., \& Mugenda G.A. (2003). Research methods: Quantitative and Qualitative approaches. Laba graphics services.

Murray, M., \& Curran, E. (2008). Learning together with parents of children with disabilities: Bringing parent-professional partnership education to a new level. Teacher Education and Special Education, 31(1), 59-63. http://dx.doi.org/10.1177/088840640803100106

Patton, M. Q. (2002). Qualitative research \& evaluation methods (3rd ed.). Thousand Oaks, CA: Sage.

Pavri, S., \& Luftig, R. L. (2000). The social face of inclusive education: are students with learning disabilities really included in the classroom? Preventing School Failure, 45(1), 8-14. http://dx.doi.org/10.1080/10459880109599808

Pavri, S. (2001). Loneliness in children with disabilities. Teaching Exceptional children, 33(6), 52-58

Pomeroy J.C. (2006). Assessment of Mental Disorders in Individuals with Intellectual Disability. In: Nain N.N., Holt G.,Davidson P.W. and Bouras N. (Eds.), Training Handbook of Mental Disorders in Individuals with Intellectual Disability. New York, NADD Press.

Schimmack, U. (2005). The structure of subjective well-being. In M. Eid \& R. Larsen (Eds.), The science of subjective well-being. New York, NY, US: Guilford Press, pp. 97-123.

Schulte M.J. (2002). Emotional intelligence: A predictive or descriptive construct in ascertaining leadership style or a new name for old knowledge? Ph.D desertion, Our lady of the Lake University, United States. Texas. Retrieved October 31, 2009, from Dissertations \& Theses: A \& I.

Smith P (2007). O'Brien, John, ed. "Have we made any progress? Including students with intellectual disabilities in regular education classrooms". Intellect Dev Disabilities, 45(5), 297-309.

Stoner, J., Bock, S. J., Thompson, J., Angell, M., Heyl, B., \& Crowley, E. (2005). Welcome to our world: Parent perceptions of interactions between parents of young children with ASD and education professionals. Focus on Autism and Other Developmental Disabilities, 20(1), 39-51. http://dx.doi.org/10.1177/10883576050200010401

UNESCO. (2006). Report by the Director General on the Global Action Plan to Achieve the Education for All Goals. Executive Board 174EX/9. Paris: UNESCO.

UNICEF. (2003). Inclusive Education Initiatives for Children with Disabilities: Lessons from the East Asia and Pacific Region. Bangkok, UNICEF.

United Nations Educational, Scientific and Cultural Organization (UNESCO) (2001). Understanding and Responding to Children's Needs in Inclusive Classrooms: A guide for Teachers. Paris: UNESCO.

Waraich, Paul, Goldner, Elliot M., Somers, Julian M., \& Hsu, Lorena. (2004). Prevalence and Incidence Studies of Mood Disorders: A Systematic Review of the Literature. Canadian Journal of Psychiatry, 49(2), 124-38.

Wu, J., Hughes, J. N., \& Kwok, O. (2010). Teacher-student relationship quality type in elementary grades: Effects on trajectories for achievement and engagement. Journal of School Psychology, 48(5), 357-387. http://dx.doi.org/10.1016/j.jsp.2010.06.004 